\title{
Global profiling of genes modified by endoplasmic reticulum stress in pancreatic beta cells reveals the early degradation of insulin mRNAs
}

\author{
P. Pirot $\cdot$ N. Naamane $\cdot$ F. Libert $\cdot$ N. E. Magnusson • \\ T. F. Orntoft • A. K. Cardozo • D. L. Eizirik
}

Received: 14 November 2006 / Accepted: 2 January 2007 / Published online: 1 March 2007

(C) Springer-Verlag 2007

\begin{abstract}
Aims/hypothesis Pancreatic beta cells respond to endoplasmic reticulum (ER) stress by activating the unfolded protein response. If the stress is prolonged, or the adaptive response fails, apoptosis is triggered. We used a 'homemade' microarray specifically designed for the study of beta cell apoptosis (the APOCHIP) to uncover mechanisms regulating beta cell responses to ER stress.

Materials and methods A time course viability and microarray analysis was performed in insulin-producing INS-1E cells exposed to the reversible ER stress inducer cyclopiazonic acid (CPA). Modification of selected genes was confirmed by real-time RT-PCR, and the observed inhibition of expression of the insulin-1 (Ins1) and insulin-2 (Ins2) genes was further characterised in primary beta cells exposed to a diverse range of agents that induce ER stress. Results CPA-induced ER stress modified the expression of 183 genes at one or more of the time points studied. The
\end{abstract}

Electronic supplementary material The online version of the article (doi:10.1001/s00125-007-0609-0) contains supplementary material, which is available to authorised users.

P. Pirot $\cdot$ N. Naamane $\cdot$ A. K. Cardozo $\cdot$ D. L. Eizirik $(\bowtie)$

Laboratory of Experimental Medicine,

Université Libre de Bruxelles (ULB),

Route de Lennik, 808-CP-618,

1070 Brussels, Belgium

e-mail: deizirik@ulb.ac.be

F. Libert

Institute of Interdisciplinary Research (IRIBHM),

Université Libre de Bruxelles (ULB),

Brussels, Belgium

N. E. Magnusson • T. F. Ørntoft

Molecular Diagnostic Laboratory,

Department of Clinical Biochemistry, Aarhus University Hospital,

Aarhus, Denmark expression of most of these genes returned to control levels after a $3 \mathrm{~h}$ recovery period following CPA removal, with all cells surviving. Two groups of genes were particularly affected by CPA, namely, those related to cellular responses to ER stress, which were mostly upregulated, and those related to differentiated beta cell functions, which were downregulated. Levels of Ins1 and Ins 2 mRNAs were severely decreased in response to CPA treatment as a result of degradation, and there was a concomitant increase in the level of IRE1 activation.

Conclusions/interpretation In this study we provide the first global analysis of beta cell molecular responses to a severe ER stress, and identify the early degradation of mRNA transcripts of the insulin genes as an important component of this response.

Keywords Apoptosis · CPA · Cyclopiazonic acid .

Diabetes mellitus · Endoplasmic reticulum stress · Insulin ·

Interleukin-1 $\cdot$ Pancreatic beta cells

\begin{tabular}{|c|c|}
\hline Abbre & \\
\hline aa-cRNA & aminoallyl antisense cRNA \\
\hline ATF & activating transcription factor \\
\hline BIP & immunoglobulin heavy chain binding protein \\
\hline CPA & cyclopiazonic acid \\
\hline $\mathrm{CHOP}$ & C/EBP homologous protein \\
\hline $\operatorname{eIF} 2 \alpha$ & eukaryotic translation initiation factor $2 \alpha$ \\
\hline ER & endoplasmic reticulum \\
\hline ERAD & ER-associated degradation pathway \\
\hline iNOS & inducible nitric oxide synthase \\
\hline INS $1 / 2$ & insulin-1/2 \\
\hline IRE1 & inositol-requiring ER-to-nucleus signal kinase 1 \\
\hline LMA & $N^{\mathrm{G}}$-methyl-L-arginine \\
\hline ORP150 & oxygen-regulated protein 150 \\
\hline CSK $1 / 2$ & proprotein convertase subtilisin/ ke \\
\hline
\end{tabular}


PERK protein kinase RNA-dependent-like ER kinase SERCA sarcoendoplasmic reticulum $\mathrm{Ca}^{2+}$-ATPase UPR unfolded protein response

XBP1 X-box binding protein 1

\section{Introduction}

Pancreatic beta cells function as nutrient sensors, responding to increases in circulating nutrients by synthesising and releasing insulin. During functional stimulation by glucose, insulin synthesis represents nearly $50 \%$ of the total protein biosynthesis by beta cells [1]. This places an enormous burden on the endoplasmic reticulum (ER), the organelle responsible for the synthesis and proper folding of secretory proteins [2], rendering beta cells vulnerable to agents that perturb ER function [3]. Disturbances in normal ER function lead to the accumulation of misfolded proteins and activate the unfolded protein response (UPR) [2]. The UPR is mediated through three ER membrane proteins, namely, protein kinase RNA-dependent-like ER kinase (PERK; also known as eukaryotic translation initiation factor 2-alpha kinase 3, EIF2AK3), activating transcription factor 6 (ATF6) and inositol-requiring ER-to-nucleus kinase 1 (IRE1; also known as ER to nucleus signalling 1, ERN1), the latter responsible for $X b p 1$ mRNA splicing and activation of the protein. The UPR decreases ER protein levels and restores ER function by (1) attenuating translation via activation of PERK and subsequent phosphorylation of the eukaryotic translation initiation factor $2 \alpha$ (eIF2 $\alpha$ ); (2) activating the transcription factors ATF6 and XBP1, which upregulate the expression of genes encoding ER chaperones and thus increase the folding capacity of the ER; and (3) degrading misfolded proteins via the ER-associated degradation pathway [4]. A fourth pathway has been recently described in Drosophila, namely, the degradation of mRNAs encoding ER-targeted proteins by IRE1, thus halting the production of new proteins in the organelle [5]. Failure of the UPR to solve ER stress leads to activation of the apoptosis pathway [6]. The mechanisms linking ER stress and apoptosis remain to be clarified, but may involve activation of the transcription factors $\mathrm{C} / \mathrm{EBP}$ homologous protein (CHOP; also known as DNA-damage-inducible transcript 3, Ddit3) and ATF3 and the kinase JNK [4, 6-9].

Homozygous mutations in the gene encoding PERK cause beta cell death and diabetes in Wolcott-Rallison syndrome in humans [10] and in a transgenic mouse model [11]. Even a partial reduction in eIF $2 \alpha$ phosphorylation, when coupled with a high-fat diet, triggers beta cell failure and diabetes [12]. Prolonged inhibition of eIF $2 \alpha$ dephosphorylation also triggers beta cell death [13], suggesting that an effective modulation of ER function is necessary for beta cell viability. In line with this, we and others have recently shown that NEFA and cytokines, agents that may contribute to beta cell death in type 2 and type 1 diabetes, respectively, cause beta cell apoptosis, at least in part, by triggering ER stress [13-18]. Moreover, beta cells are particularly sensitive to agents that deplete $\mathrm{ER} \mathrm{Ca}^{2+}$, such as the sarcoendoplasmic reticulum $\mathrm{Ca}^{2+}$-ATPase (SERCA) blockers cyclopiazonic acid (CPA) and thapsigargin [15, $18,19]$. We have recently shown that exposure of INS-1E cells to CPA for 6-12 h triggers severe ER stress, characterised by increased Chop, Bip (also known as heatshock $70 \mathrm{kDa}$ protein 5, Hspa5) and Xbpl spliced mRNA expression and activation of a UPR-luciferase reporter construct [18].

Against this background, we have combined highthroughput and conventional experimental approaches to reveal the mechanisms regulating beta cell responses to ER stress. For this purpose, we used an 'in-house' spotted rat oligonucleotide microarray, the APOCHIP, containing 60mer probes for nearly 600 genes selected for the study of beta cell apoptosis [20]. The APOCHIP provides reproducible data, and compares well with the Affymetrix GenChip [20]. Time-dependent profiles of the genes available in the APOCHIP were measured in INS-1E cells exposed to the reversible SERCA blocker CPA to create an ER stress compendium of several thousand measures. Elucidation of the global pattern of beta cell gene expression in response to ER stress involved statistical analysis of this large data set and confirmation by real-time RT-PCR of some genes. The results of this experiment indicated that ER stress causes an early and marked decrease in Ins $1 / 2$ mRNA expression, and this was independently tested in insulinproducing cells and primary beta cells exposed to CPA, thapsigargin or cytokines (IFN- $\gamma+\mathrm{IL}-1 \beta$ ).

\section{Materials and methods}

Cell culture and treatments INS-1E cells were cultured in RPMI 1640 medium (Invitrogen, Paisley, Scotland) [21], while primary rat beta cells were FACS purified and cultured in Ham's F-10 medium (Invitrogen) [21]. Cells were plated and cultured for $48 \mathrm{~h}$ prior to the addition of test agents. The SERCA blockers - CPA and thapsigargin - were solubilised in DMSO and were used at concentrations of $25 \mu \mathrm{mol} / 1$ and $1 \mu \mathrm{mol} / 1$, respectively. DMSO $(0.125 \%)$ was used as the control condition in the experiments involving SERCA blockers. This concentration of DMSO does not affect gene expression or survival in INS-1E or primary beta cells ([15, 18]; data not shown). Recombinant rat IFN- $\gamma$ (R\&D Systems, Abingdon, UK) was used at a concentration of $0.036 \mu \mathrm{g} / \mathrm{ml}( \pm 100 \mathrm{U} / \mathrm{ml})$, and human recombinant IL-1 $\beta$ (a gift from C.W. Reinolds, National Cancer Institute, Bethesda, 
MD, USA) was used at a concentration of $10 \mathrm{U} / \mathrm{ml}$ for the INS-1E cell experiments and $50 \mathrm{U} / \mathrm{ml}$ for the primary beta cell experiments. The inducible NO synthase (iNOS) blocker $N^{\mathrm{G}}$-methyl-L-arginine (LMA; Sigma, Steinheim, Germany) was used at $1.0 \mathrm{mmol} / \mathrm{l}$. CPA, thapsigargin, cytokines and LMA concentrations were selected based on our previous time course and dose-response studies [15, 18, 22].

Assessment of INS-1E cells viability INS-1E cells were exposed to CPA or DMSO (control) for the time periods indicated. CPA was then removed by changing the medium, and the cells were subsequently incubated for a further $24 \mathrm{~h}$ before assessment of viability. For comparison, cells in some experiments were also treated with CPA for the last 9 and $12 \mathrm{~h}$ of the experiment. The percentage of viable, apoptotic and necrotic cells was determined as previously described $[15,18]$.

Preparation of the target for array analysis INS-1E cells were exposed to CPA or DMSO (control) for 2, 6 or $12 \mathrm{~h}$, or for $6 \mathrm{~h}$ followed by a $3 \mathrm{~h}$ recovery period in the absence of CPA. Cells were then collected, and total RNA was isolated using the RNeasy Mini Kit (Qiagen, Venlo, The Netherlands). Double-stranded cDNA was prepared and was used as template for aminoallyl antisense cRNA (aacRNA) synthesis [20]. The aa-cRNA was purified and coupled to a fluorophore, either indocarbocyanine (Cy3) or indodicarbocyanine (Cy5) (Amersham, Diegem, Belgium). The labelled aa-cRNA was fragmented, precipitated and resuspended in RNAse-free water for spectrometric quantification [20].

Hybridisation and data analysis An aliquot $(1 \mu \mathrm{g})$ of control target was mixed with $1 \mu \mathrm{g}$ of CPA target labelled with the other fluorophore; all hybridisations were replicated with dyes swapped [20]. Microarrays were scanned with a GenePix 4000B scanner (Axon Instruments, Union City, CA, USA). Spot and surrounding local background intensities were quantified with GenePix Pro 5.0 (Axon Instruments) using the irregular spot feature. The gene expression $\log _{2}$-ratios were calculated from the spot intensities (with background intensity subtracted) and used for normalisation. Housekeeping gene-based Lowess normalisation of the microarray data was carried out using the tRMA package [23] written in R code (http://cran.r-project.org, last accessed in January 2007). The normalised $\log _{2}$-ratios of each dye swap were averaged. The means for the three independent experiments were then used for a Student's $t$ test. To address the problem of multiple hypothesis testing, a method controlling for a false discovery rate (FDR) was applied $[24,25]$ using the Q-value package (http://faculty.washington. edu/ jstorey/qvalue/, last accessed in January 2007). Genes were considered as significantly modified by CPA if they had a $q$ value equal or less than 0.06 (FDR of $6 \%$ among the significant genes) for at least one of the four time points studied.

Real-time RT-PCR, RNA stability and Ins 1 promoter activity Cells were collected for mRNA extraction followed by reverse transcription [26]. The medium of cells treated with cytokines and/or LMA was collected for nitrite determination (nitrite is a stable product of $\mathrm{NO}$ oxidation) using the Griess method [27]. Expression of the insulin-1 (Ins I) and insulin-2 (Ins2) genes and levels of spliced Xbpl $(X b p 1 \mathrm{~s})$ were measured by real-time quantitative RT-PCR using the standard curve method [14]. The housekeeping gene glyceraldehyde-3-phosphate dehydrogenase (Gapdh) was used for confirmation of similar cDNA loading. Gapdh expression in INS-1E cells was not modified by the different experimental treatments (data not shown), apart from an observed $20-30 \%$ decrease $(p \leq 0.01)$ following $12 \mathrm{~h}$ exposure to CPA, which is in line with the observed decrease in cell viability at this time point (Fig. 1). The values for each amplified cDNA were corrected for Gapdh and normalised, with a maximum value of 1 used in each experiment. The specific primers used and their respective PCR fragment lengths (in brackets) were as follows: $X b p 1 \mathrm{~s}$ Forward 5'-GAGTCCGCAGCAGGTG-3', Reverse 5'-GC GTCAGAATCCATGGGA-3' (65 bp); Ins 1 Forward 5'-AC CTTTGTGGTCCTCACCTG-3', Reverse 5'-AGCTCCAG TTGTGGCACTTG-3' (118 bp); and Ins2 Forward 5'-TGT GGTTCTCACTTGGTGGA-3', Reverse 5'-CTCCA GTTGTGCCACTTGTG-3' (111 bp). The primers used for ATF4, Bip, calbindin, calreticulin, Grp94, Sec61 and Gapdh have been described previously $[15,18]$. For RNA stability experiments, INS-1E cells were exposed to CPA or DMSO (control) for $6 \mathrm{~h}$ in the presence of actinomycin D $(4 \mathrm{ng} / \mathrm{ml})$ to block new mRNA synthesis. Cells were collected every 30-60 min and then processed using real-time RT-PCR to detect Ins1, Ins2 and Gapdh mRNAs as described above.

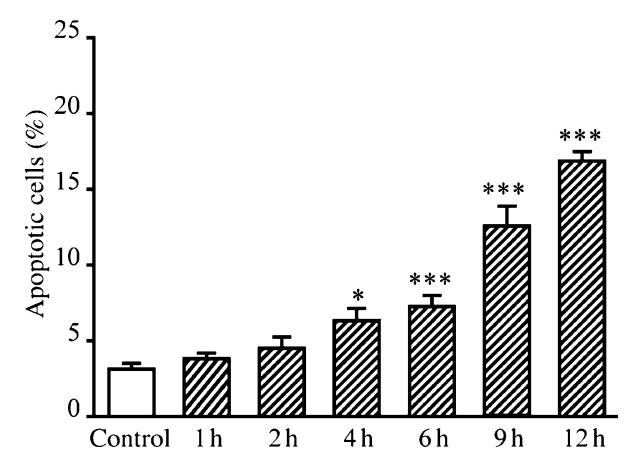

Fig. 1 CPA-induced INS-1E cell apoptosis. INS-1E cells were treated with CPA $(25 \mu \mathrm{mol} / 1$, striped bars $)$ for the indicated time periods or for $12 \mathrm{~h}$ with DMSO (control, white bar) and then further cultured for $24 \mathrm{~h}$ in CPA-free medium. Data are expressed as the percentage of the total number of cells counted $\pm \operatorname{SEM}(n=3-6) .{ }^{*} p \leq 0.05, * * * p \leq 0.001$ vs control 
For assessment of Ins 1 promoter activity, INS-1E cells were transfected using lipofectamine (Invitrogen) with $250 \mathrm{ng}$ of the rat Ins 1 promoter-luciferase construct (a kind gift from G. Holz, New York University School of Medicine, New York, NY, USA) [28], and the pRL-CMV plasmid (50 ng; with Renilla luciferase used as an internal control for transfection efficiency). Twenty-four hours after transfection the cells were exposed to CPA or DMSO (control) for 6 or $12 \mathrm{~h}$. Luciferase activities in the cell lysates were determined and expressed as firefly/Renilla (relative luciferase activity).

Statistical analysis Data are shown as means \pm SEM, and comparisons between groups were made by the paired Student's $t$ test or by ANOVA followed by the Student's $t$ test with the Bonferroni correction, as indicated. A $p$ value of $\leq 0.05$ was considered statistically significant.

\section{Results}

Viability of INS-1E cells exposed to a CPA-induced ER stress In the presence of CPA, the percentage of apoptotic INS-1E cells had increased by the $4 \mathrm{~h}$ time point, and increased with time to study end, with $17 \%$ of cells apoptotic by the $12 \mathrm{~h}$ time point (Fig. 1). There was no significant increase in the proportion of necrotic cells (data not shown), confirming our previous observations that SERCA blockers kill beta cells by apoptosis [15, 18]. When beta cells were exposed to CPA for $9 \mathrm{~h}$, and then washed and cultured for an additional $24 \mathrm{~h}$ without the SERCA blocker, the percentage of apoptotic cells was similar to that observed in beta cells exposed to CPA alone for $9 \mathrm{~h}(12.5 \pm 1.3 \%$ vs $12.7 \pm 1.2 \%$, respectively; means \pm SEM, $n=4)$. Similar results were observed after exposure to $\mathrm{CPA}$ for $12 \mathrm{~h}$, with or without a further $24 \mathrm{~h}$ incubation in medium alone (data not shown). This indicates that the effects of CPA are reversible, and suggests that beta cells trigger defence mechanisms that allow them to survive and recover once ER stress is removed. Based on these and previous experiments [18], we selected periods of 2, 6 and $12 \mathrm{~h}$ exposure to CPA for the subsequent array analysis. An additional group of cells exposed to CPA for $6 \mathrm{~h}$, followed by a $3 \mathrm{~h}$ recovery period, was included to allow the identification of genes expressed in the early phase of ER stress recovery.

Identification of ER stress-modified genes by microarray analysis Three independent CPA time course experiments were conducted as described above. In the INS-1E cells, 491 genes, represented by 867 spots (each spot containing a different probe) flagged as 'good' by the GenePix Pro 5.0 software, were detected (this material can be provided upon request, and will be subsequently deposited at the Beta-cell Gene Expression Bank at http://t1dbase.org, last accessed in January 2007). CPA-induced ER stress modified the expression of 183 genes $( \pm 40 \%$ of the total; $p \leq 0.05$ and $q \leq 0.06)$ at one or more of the time points studied (Electronic supplementary material [ESM] Table 1). There were few modifications in gene expression after $2 \mathrm{~h}$ of CPA exposure (Fig. 2a), but after 6 and 12 h, 68 and 168 genes, respectively, were differently expressed compared with controls $(p \leq 0.05$ and $q \leq 0.06)$. A $3 \mathrm{~h}$ recovery period following $6 \mathrm{~h}$ exposure to CPA allowed levels of most mRNAs to return to control values (ESM Table 1, Fig. 2d). While $6 \mathrm{~h}$ exposure to CPA changed the expression of 60 genes by more than $30 \%$, the additional $3 \mathrm{~h}$ recovery period reduced this number to $36(p \leq 0.05)$.

The genes present in the APOCHIP were clustered in 14 groups according to their putative biological function. Genes from nearly all clusters were affected by CPA (ESM Table 1), indicating the profound functional repercussions of ER stress in beta cells. Two groups of genes were particularly affected by CPA, namely, those related to ER stress (most of which were upregulated) and those related to differentiated beta cell functions (most of which were downregulated). The expression of the genes encoding the ER chaperones Bip, calreticulin and Grp94, the ER stress-related transcription factors ATF4, ATF3 and Chop, the pro-apoptotic caspase 12 and the ER protein translocator Sec61 was upregulated, while the expression of the gene for cyclin D1 was inhibited. Six of these genes were selected for confirmation by real-time RT-PCR in an
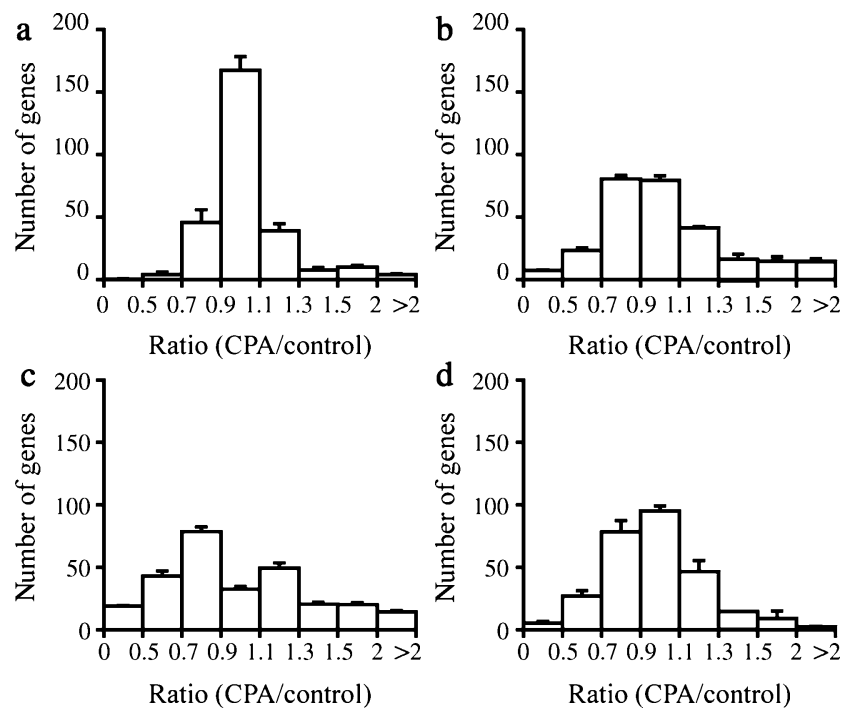

Fig. 2 Histogram presenting the global CPA-induced modifications in gene expression. Data are expressed as a normalised ratio of the measured intensity in the CPA-treated condition to the measured intensity under the control (DMSO) condition (CPA/control) at the different time points studied $(\mathbf{a}, 2 \mathrm{~h} ; \mathbf{b}, 6 \mathrm{~h} ; \mathbf{c}, 12 \mathrm{~h} ; \mathbf{d}, 6 \mathrm{~h}+3 \mathrm{~h}$ recovery) 
Table 1 Confirmation by real-time RT-PCR of CPA-induced modifications in mRNA expression of a selected set of changed genes from the microarray experiment

\begin{tabular}{llcll}
\hline Description & $\begin{array}{l}\text { APOCHIP } \\
6 \mathrm{~h}\end{array}$ & $\begin{array}{l}\text { RT-PCR } \\
6 \mathrm{~h}\end{array}$ & $\begin{array}{l}\text { APOCHIP } \\
12 \mathrm{~h}\end{array}$ & $\begin{array}{l}\text { RT-PCR } \\
12 \mathrm{~h}\end{array}$ \\
\hline ATF4 & $2.5 \pm 0.2^{* *}$ & $5.7 \pm 0.9^{* *}$ & $2.6 \pm 0.2^{*}$ & $7.6 \pm 0.6^{* * *}$ \\
Bip & $2.6 \pm 0.3^{*}$ & $3.3 \pm 0.5^{* *}$ & $3.1 \pm 0.3^{* *}$ & $6.2 \pm 1^{* *}$ \\
Calbindin & $0.9 \pm 0.02^{*}$ & $1 \pm 0.1$ & $0.8 \pm 0.03^{*}$ & $0.9 \pm 0.1$ \\
Calreticulin & $1.3 \pm 0.08^{*}$ & $2.6 \pm 0.4^{*}$ & $1.5 \pm 0.1^{*}$ & $4.4 \pm 0.4^{* *}$ \\
Grp94 & $1.5 \pm 0.3$ & $2.8 \pm 0.6^{*}$ & $2.1 \pm 0.3^{*}$ & $4.9 \pm 1.1^{*}$ \\
Sec61 & $1.3 \pm 0.05^{*}$ & $3.6 \pm 0.5^{* *}$ & $1.6 \pm 0.1^{* *}$ & $4.1 \pm 0.4^{* *}$
\end{tabular}

The APOCHIP and real time RT-PCR data are expressed as mean fold change of respectively three and six independent experiments \pm SEM. ${ }^{*} p \leq 0.05 ; * * p \leq 0.01 ; * * * p \leq 0.001$ vs control (DMSO), $t$ test

independent series of experiments (Table 1). We have recently shown that CPA induces Chop mRNA expression [18], and so these experiments were not repeated here. Real-time RT-PCR performed on independent material confirmed CPA-induced ATF4, Bip, calreticulin, Grp94 and Sec61 mRNA expression, but failed to detect a marginal $10-20 \%$ decrease in calbindin mRNA expression, observed with the APOCHIP. There was excellent agreement between the APOCHIP and real-time RT-PCR regarding qualitative changes in gene expression, but the observed quantitative changes were 1.5-2.0-fold lower in the APOCHIP as compared with real-time RT-PCR. Similar findings have been reported in other array systems [29], and may be an inherent limitation of this system. The expression of the genes encoding the pro-apoptotic transcription factors ATF3 and Chop returned to basal levels after the $3 \mathrm{~h}$ recovery period, while expression of the genes encoding the key ER chaperones Bip and Grp94 remained elevated (ESM Table 1).

Another group of genes modified by ER stress were those involved in beta cell differentiated functions (ESM Table 1). Thus, we observed a decrease in the expression of Ins2, Pcsk1, Pcsk2, Rab3a, Pdx-1, Isl-1, HNF-1 $\alpha$ and HNF-3 $\alpha$. Inhibition was most marked for Ins 2 , the expression of which was decreased by $60-80 \%$ after $6-12$ h (ESM Table 1). We also observed a $50 \%$ decrease in levels of Ins 1 transcript after 6-12 h (data not shown); however, this gene failed to pass our statistical test.

$E R$ stress induces a marked decrease in insulin mRNA expression in INS-1E cells and primary beta cells We confirmed the CPA-induced decrease in Ins1 and Ins2 mRNAs using real-time RT-PCR (Fig. 3a,b). At $2 \mathrm{~h}$ there were already $40 \%$ decreases in the expression of Ins 1 and Ins 2, with maximal reductions observed at $12 \mathrm{~h}(90 \%$ decrease). After the $3 \mathrm{~h}$ recovery period, although there was an increase in both mRNAs, they did not return to control levels. Thapsigargin induced a similar inhibition in Ins 1 and
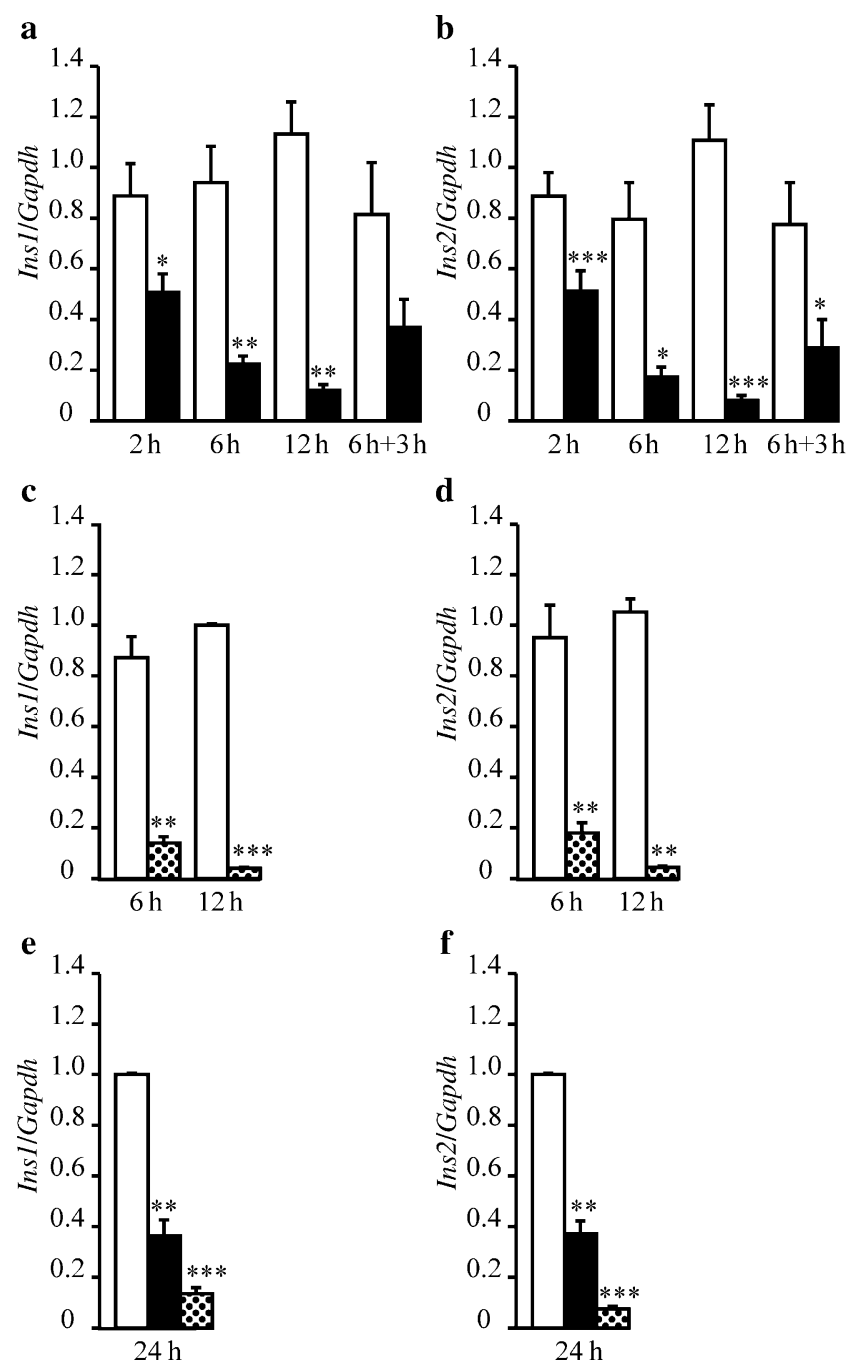

Fig. 3 Decrease in the expression of Ins1 and Ins2 mRNAs in INS$1 \mathrm{E}$ and primary beta cells exposed to chemical ER stressors. INS-1E (a-d) or primary beta $(\mathbf{e}, \mathbf{f})$ cells were exposed to the SERCA blockers CPA $(25 \mu \mathrm{mol} / 1$, black bars $)$ or thapsigargin $(1 \mu \mathrm{mol} / 1$, dotted bars $)$, or to DMSO (control, white bars) for the indicated time periods. Cells were then processed for real-time RT-PCR analysis using specific primers for Ins $1(\mathbf{a}, \mathbf{c}, \mathbf{e})$ and Ins $2(\mathbf{b}, \mathbf{d}, \mathbf{f})$. The data shown are the means \pm SEM of three to four independent experiments corrected for Gapdh expression. ${ }^{*} p \leq 0.05 ; * * p \leq 0.01 ; * * * p \leq 0.001$ vs control, Student's $t$ test

Ins 2 mRNAs, with a $80-95 \%$ decrease in levels of transcripts of Ins 1 and Ins 2 after 6 and 12 h, respectively (Fig. 3c,d). In parallel experiments, primary beta cells were exposed to CPA or thapsigargin for $24 \mathrm{~h}$ (a longer time point was selected for these experiments because primary beta cells are more resistant than INS-1E cells to induction of ER stress and apoptosis by SERCA blockers [15]). Similar results to those in INS-1E cells were observed; both agents induced severe decreases in Ins 1 and Ins 2 mRNAs (Fig. 3e,f).

The cytokines IFN- $\gamma+$ IL- $1 \beta$ induce ER stress via NO formation [15]. Exposure of both INS-1E cells (Fig. 4a,b) and primary beta cells (Fig. 4c,d) to cytokines inhibited the 

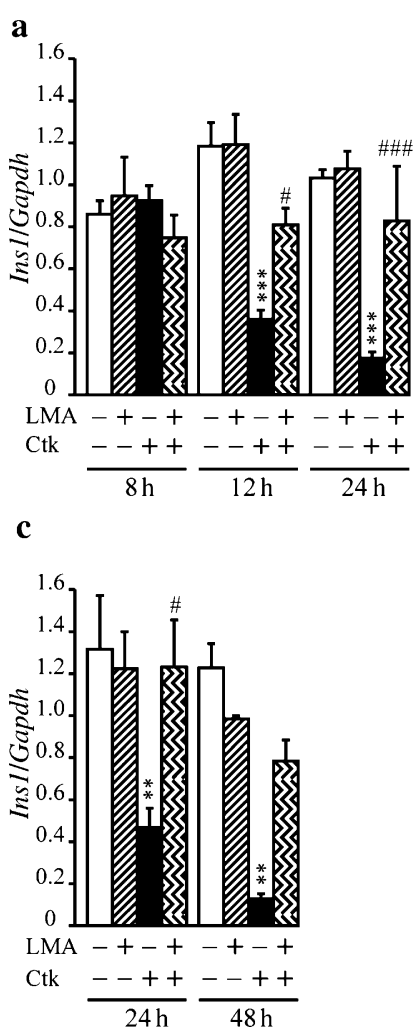

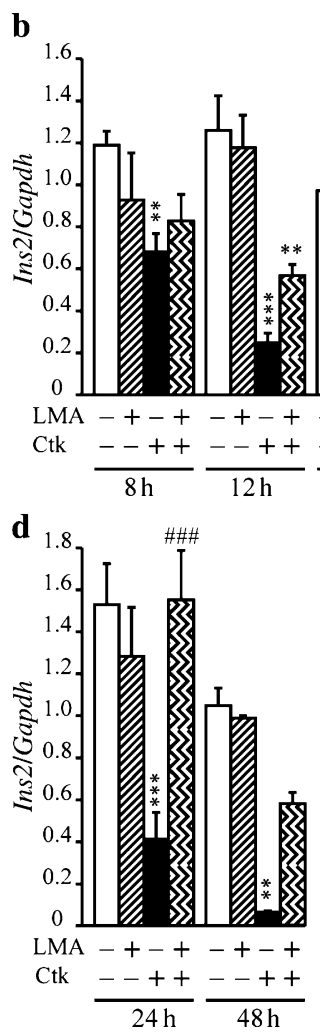

Fig. 4 Decrease in the expression of Ins 1 and Ins 2 mRNAs in INS-1E and pancreatic beta cells exposed to cytokines. INS-1E $(\mathbf{a}, \mathbf{b})$ or primary beta $(\mathbf{c}, \mathbf{d})$ cells were exposed to IFN- $\gamma(0.036 \mu \mathrm{g} / \mu \mathrm{l})+\mathrm{IL}-$ $1 \beta(10 \mathrm{U} / \mathrm{ml})(\mathrm{Ctk})$ in the presence or absence of LMA $(1 \mathrm{mmol} / \mathrm{l})$, or left untreated (control) for the indicated time periods. Cells were collected for mRNA extraction, and real-time RT-PCR was performed for Ins1 (a, c) and Ins2 (b, d). The data shown are the means \pm SEM of three to eight independent experiments corrected for Gapdh expres-

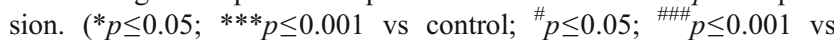
Ctk ANOVA followed by Student's $t$ test with Bonferroni correction)

expression of Ins 1 and Ins 2 after 12-24 $\mathrm{h}$ and 24-48 h, respectively. The iNOS blocker LMA prevented cytokineinduced nitrite formation (data not shown) and the decrease in $\operatorname{Ins} 1 / 2$ mRNA expression.

To assess the effects of ER stress on Ins $1 / 2$ mRNA stability, INS-1E cells were treated with actinomycin D (to arrest new mRNA synthesis) and either CPA or DMSO (control).The expression of Ins 1 and Ins 2 mRNAs in the control group did not change during the $6 \mathrm{~h}$ follow-up (Fig. 5a,b), whereas the expression of both mRNAs was reduced by $31-37 \%$ after exposure to CPA for $1 \mathrm{~h}$, with $50 \%$ reductions observed in the subsequent hours. To evaluate whether inhibition of transcription contributes to the decrease in Ins1/2 mRNA, INS-1E cells were transfected with a luciferase reporter construct containing the rat Ins 1 promoter [28] and were treated with CPA or DMSO for 6 and $12 \mathrm{~h}$. CPA had no effect on Ins 1 promoter activity (64 77 vs $68 \pm 6$ and $70 \pm 9$ vs $83 \pm 19$; DMSO (control) vs $\mathrm{CPA}$ at 6 and $12 \mathrm{~h}$, respectively, $n=3$ ). Thus, the ER stress- a

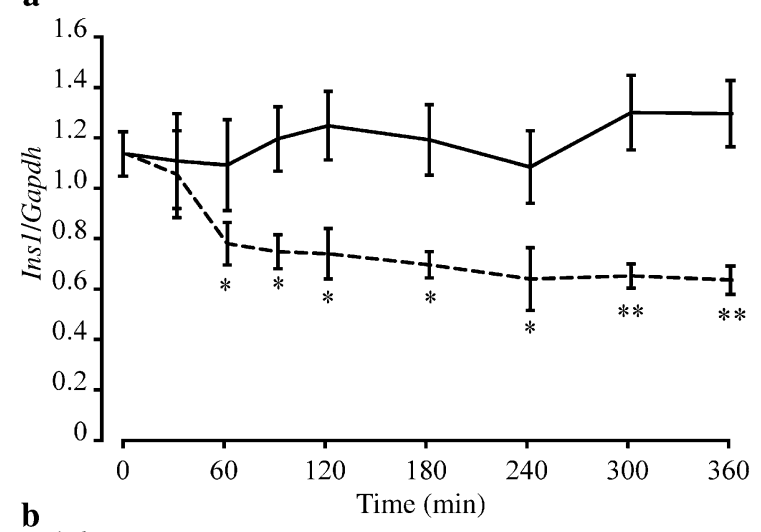

b

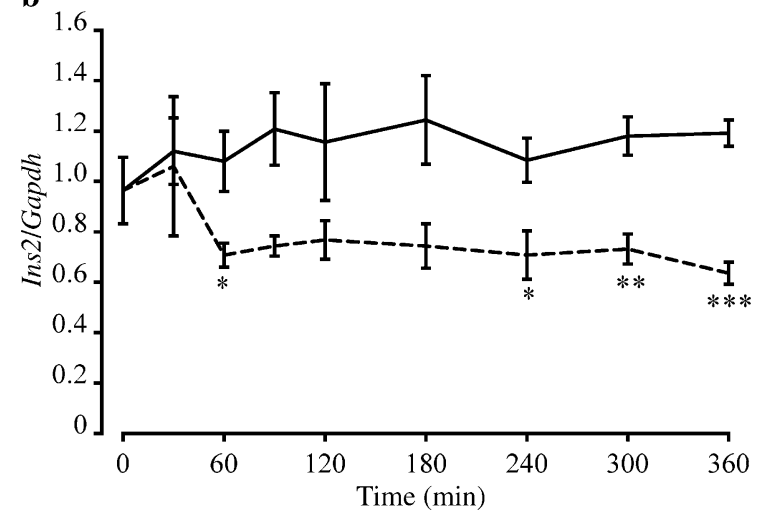

Fig. 5 Ins 1 and Ins 2 mRNA stability in INS-1E cells exposed to CPA. INS-1E cells were exposed to actinomycin D $(4 \mathrm{ng} / \mu \mathrm{l})$ in the presence of CPA $(25 \mu \mathrm{mol} / 1$, dotted line) or DMSO (control, solid line) for up to $360 \mathrm{~min}$. Cells were then collected for mRNA extraction, and real-time RT-PCR was performed for Ins 1 (a) and Ins2 (b). The data shown are the means \pm SEM of four experiments, corrected for Gapdh expression. ${ }^{*} p \leq 0.05,{ }^{* *} p \leq 0.01,{ }^{* * *} p \leq 0.001$ vs control (DMSO + actinomycin D), Student's $t$ test

induced decrease in Ins $1 / 2$ mRNA levels is mainly due to the early degradation of these transcripts.

Activation of the IRE1 pathway may cause transcript degradation of ER-targeted genes [5]. We evaluated IRE1 activity by measuring $X b p 1$ splicing ( $X b p 1$ is a target of IRE1 endonuclease activity [4]). CPA led to an early ( $2 \mathrm{~h})$ and marked (4.5-fold) increase in $X b p 1 \mathrm{~s}$, which remained augmented for up to $12 \mathrm{~h}$ (Fig. 6). Levels of Xbpls returned to control values as soon as CPA was removed (Fig. 6). Similar findings were obtained using a restriction enzyme method to determine Xbpl splicing ([18]; data not shown).

\section{Discussion}

In the present study we used the APOCHIP, a rat oligonucleotide microarray [20], to determine the molecular mechanisms regulating beta cell responses to ER stress. Two groups of genes were particularly sensitive to CPA: those involved in the response to ER stress, which were 


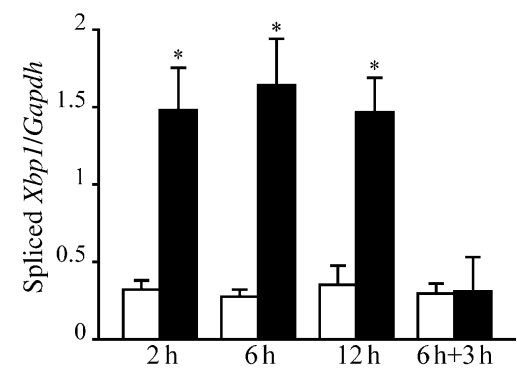

Fig. 6 CPA activates the IRE1 pathway in insulin producing cells. INS-1E cells were exposed to CPA $(25 \mu \mathrm{mol} / 1$ black bars $)$ or DMSO (control, white bars) for the indicated times points. Cells were then processed for real-time RT-PCR analysis using specific primers for the spliced form of $X b p 1$. The data shown are means \pm SEM of three to four experiments corrected for Gapdh expression. ${ }^{*} p \leq 0.05$ vs control (DMSO), Student's $t$ test

mostly upregulated, and those related to differentiated beta cell functions, which were mostly downregulated.

The genes encoding the ER chaperones Bip, calreticulin and Grp94, the ER stress-related transcription factors ATF4, ATF3 and Chop, the pro-apoptotic caspase 12 and the ERprotein translocator Sec61 were all upregulated by CPA, while the gene for cyclin D1 was inhibited during ER stress as a mechanism to prevent cell division [30]. Bip, Grp94 and calreticulin - three of the most abundant chaperones in the ER - are involved in the correct folding of nascent protein. They also carry out the following important functions in this organelle: (1) Bip and calreticulin are involved in the ER 'quality control' system, which leads to the destruction of malfolded proteins via the ER-associated degradation pathway (ERAD) via the proteasome [31, 32]; (2) Grp94 and calreticulin have a high calcium binding capacity, and are therefore involved in $\mathrm{ER} \mathrm{Ca}^{2+}$ homeostasis [32, 33]; (3) Bip also plays a key role in the regulation of the three UPR transducer proteins ATF6, PERK and IRE1 via a binding-release mechanism [31]. Sec61 is involved in the formation of channels across the ER membrane, permitting the evacuation of malfolded protein from the ER lumen to proteasomes in the cytosol [34]. The transcription factor ATF4 regulates a set of protective genes related to amino acid import/metabolism and resistance to oxidative stress [35], and is also involved in the regulation of the pro-apoptotic protein Chop [36, 37]. ATF3, Chop and caspase 12 are three potential mediators of ER stresstriggered beta cell apoptosis, as suggested by (1) partial protection against cell death in Chop knockout islets exposed to NO [8] and in ATF3-deficient islets exposed to IFN- $\gamma$ plus IL-1 $\beta$ [7]; (2) Delayed diabetes onset in Akita mice with an homozygous deletion of Chop [9]; (3) decreased expression of $B c l 2$ in Chop-overexpressing cells [38], an effect suggested in the present study by the inverse relationship between Chop and Bcl2 expression (ESM Table 1) (4) resistance of renal tubular epithelium and neurons from caspase 12 null mutant mice to ER stress- induced apoptosis [39]; (5) diabetic phenotype secondary to beta cell loss in mice overexpressing ATF3 [7].

In the present study, expression of ATF3 and Chop returned to basal levels after the $3 \mathrm{~h}$ recovery period, while expression of the Bip and Grp94 remained elevated. This pattern of gene expression may explain how beta cells endure 9-12 $\mathrm{h}$ of severe ER stress without reaching the 'point of no return' for cell death; indeed, as soon as CPA was removed, the induction of apoptosis was arrested in the surviving cells.

CPA induced a marked decrease in the expression of several genes involved in the maintenance of a beta cell differentiated phenotype. There was a decrease in the expression of Ins2, Pcsk1/2 (whose protein products, the prohormone convertases 1 and 2 , are responsible for the conversion of proinsulin to insulin [40]), Rab3a (which encodes Ras-related small GTP binding protein 3A, involved in insulin exocytosis [41]) and $P d x-1, I s l-1$, $H N F-1 \alpha$ and $H N F-3 \alpha$ (which encode transcription factors involved in the maintenance of a differentiated beta cell phenotype [42]). Beta cell exposure to the cytokines IFN$\gamma$ and IL-1 $\beta$, which induce ER stress [15], results in the inhibition of expression of Pcsk1/2, impairing the conversion of pro-insulin into insulin $[43,44]$, and the decreased expression of $P d x-1$ and $I s l-1$ [26]. These cytokines also decrease the expression of $S N A P-25, V A M P-2$ and Rab3a, whose protein products are involved in granule fusion with the beta cell membrane [22, 45], preferentially decreasing the first phase of exocytosis [45]. The present data suggest that these effects of cytokines are, at least in part, secondary to ER stress.

The most marked effect of CPA was the decrease in the expression of Ins 1 and Ins 2 mRNAs. Similar findings were observed in INS-1E cells exposed to thapsigargin or cytokines (IFN- $\gamma$ plus IL-1 $\beta$ ) and in primary beta cells exposed to the same agents. Cytokines inhibit Ins $1 / 2$ mRNA expression and pro-insulin biosynthesis in rat and mouse islets [46-48]. The decrease in Ins1/2 levels is secondary to NO production [22], a finding confirmed in the present study. Cytokine-induced ER stress is prevented by iNOS blockers [15], suggesting that the inhibitory effects of cytokines on Ins 1/2 mRNA expression are, at least partly, secondary to ER stress.

It has been recently shown that ER stress causes the rapid degradation of mRNAs targeted for translation at the ER in Drosophila cells. This degradation is mediated by IRE1 activation, and complements other UPR mechanisms by selectively halting the production of non-vital proteins at the ER [5]. The two insulin gene transcripts are the most abundant mRNAs directed to the ER of rat beta cells, and a rapid decrease in Ins $1 / 2 \mathrm{mRNA}$ expression could represent a novel mechanism of beta cell adaptation to ER stress. Against this background, we evaluated whether CPA- 
induced ER stress activates the IRE1 pathway in INS-1E cells, as measured by Xbpl splicing, and whether the observed decrease in Ins $1 / 2$ mRNA is due to mRNA degradation. Our results indicated that this was indeed the case. Thus, CPA induced early and intense Xbpl splicing, which was paralleled by the early degradation of both Ins 1 and Ins 2 without affecting the activity of the Ins 1 promoter.

Acute 'physiological' and prolonged 'pathological' exposure to high glucose triggers several markers of the UPR; however, while short-term (1-3 h) exposure to high glucose favours insulin biosynthesis, long-term (3-7 days) exposure decreases Ins $1 / 2$ mRNA expression [49]. Phosphorylation of IRE $1 \alpha$ is observed under both conditions, but Xbpl splicing is only detectable after a long term exposure to high glucose [49]. Xbpl splicing therefore seems to be a marker that differentiates between 'physiological' and 'pathological' activation of the UPR. In this study, CPA exposure clearly induced Xbpl splicing (Fig. 6). In addition, we have recently completed another study on the regulation of Chop mRNA expression by diverse ER stresses in insulin-producing cells [37], where the effects of $\mathrm{CPA}$, at the concentration used in the present study, induced ER stress similar to that induced by cytokines and by the NEFA palmitate. Moreover, it was recently described that ER stress markers are present in islets obtained from diabetic $d b / d b$ mice and patients with type 2 diabetes [50]. These observations suggest that the present data reflects a 'pathological' beta cell situation of potential relevance to the diabetic state.

The present study reports the first global analysis of beta cell molecular responses to severe ER stress, and identifies the early degradation of Ins 1 and Ins2 mRNAs as an important component of this response. We suggest that massive degradation of Ins $1 / 2$ mRNA, the most prevalent ER-targeted mRNA in beta cells, alleviates functional demand on the ER. This, together with a vigorous upregulation of ER chaperones, contributes to beta cell survival and recovery once the source of ER stress is removed.

Acknowledgements This work was supported by grants from the European Union (STREP SAVEBETA, contract no. 036903 in the Framework Programme 6 of the European Community), the Fonds National de la Recherche Scientifique (FNRS; National Fund for Scientific Research; Belgium) and the 'Communauté française de Belgique-Actions de Recherche Concertées' (ARC; French Community of Belgium-Concerted Research Actions) to D. L. Eizirik, and a JDRF Transition Award Grant to A. K. Cardozo. We gratefully acknowledge G. Høj for advice on the microarray procedure and G. Pirot for developing the handmade tools to dry the arrays. We also thank M. A. Neef, G. Vandenbroeck and R. Leeman for excellent technical support. This paper is dedicated to the memory of Professor Claes Hellerström, who made many crucial contributions to our understanding of pancreatic beta cell function and dysfunction.
Duality of interest The authors declare that they have no duality of interest in connection with this study.

\section{References}

1. Schuit FC, In't Veld PA, Pipeleers DG (1988) Glucose stimulates proinsulin biosynthesis by a dose-dependent recruitment of pancreatic beta cells. Proc Natl Acad Sci USA 85:3865-3869

2. Schroder M, Kaufman RJ (2005) The mammalian unfolded protein response. Annu Rev Biochem 74:739-789

3. Harding HP, Ron D (2002) Endoplasmic reticulum stress and the development of diabetes: a review. Diabetes 51(Suppl 3):S455-S461

4. Schroder M, Kaufman RJ (2006) Divergent roles of IRE1alpha and PERK in the unfolded protein response. Curr Mol Med 6:5-36

5. Hollien J, Weissman JS (2006) Decay of endoplasmic reticulumlocalized mRNAs during the unfolded protein response. Science 313:104-107

6. Xu C, Bailly-Maitre B, Reed JC (2005) Endoplasmic reticulum stress: cell life and death decisions. J Clin Invest 115:2656-2664

7. Hartman MG, Lu D, Kim ML et al (2004) Role for activating transcription factor 3 in stress-induced beta-cell apoptosis. Mol Cell Biol 24:5721-5732

8. Oyadomari S, Takeda K, Takiguchi M et al (2001) Nitric oxideinduced apoptosis in pancreatic beta cells is mediated by the endoplasmic reticulum stress pathway. Proc Natl Acad Sci USA 98:10845-10850

9. Oyadomari S, Koizumi A, Takeda K et al (2002) Targeted disruption of the Chop gene delays endoplasmic reticulum stress-mediated diabetes. J Clin Invest 109:525-532

10. Delepine M, Nicolino M, Barrett T, Golamaully M, Lathrop GM, Julier C (2000) EIF2AK3, encoding translation initiation factor 2alpha kinase 3 , is mutated in patients with Wolcott-Rallison syndrome. Nat Genet 25:406-409

11. Harding HP, Zeng H, Zhang Y et al (2001) Diabetes mellitus and exocrine pancreatic dysfunction in perk $-/-$ mice reveals a role for translational control in secretory cell survival. Mol Cell 7:1153-1163

12. Scheuner D, Mierde DV, Song B et al (2005) Control of mRNA translation preserves endoplasmic reticulum function in beta cells and maintains glucose homeostasis. Nat Med 11:757-764

13. Cnop M, Ladriere L, Hekerman P et al (2007) Selective inhibition of eIF $2 \alpha$ dephosphorylation potentiates fatty acid-induced ER stress and causes pancreatic $\beta$-cell dysfunction and apoptosis. J Biol Chem 282:3989-3997

14. Kharroubi I, Ladriere L, Cardozo AK, Dogusan Z, Cnop M, Eizirik DL (2004) Free fatty acids and cytokines induce pancreatic beta-cell apoptosis by different mechanisms: role of nuclear factor-kappaB and endoplasmic reticulum stress. Endocrinology 145:5087-5096

15. Cardozo AK, Ortis F, Storling J et al (2005) Cytokines downregulate the sarcoendoplasmic reticulum pump $\mathrm{Ca}^{2+}$ ATPase $2 \mathrm{~b}$ and deplete endoplasmic reticulum $\mathrm{Ca}^{2+}$, leading to induction of endoplasmic reticulum stress in pancreatic $\beta$-cells. Diabetes 54:452-461

16. Cnop M, Welsh N, Jonas JC et al (2005) Mechanisms of pancreatic $\beta$-cell death in type 1 and type 2 diabetes: many differences, few similarities. Diabetes 54(Suppl 2):S97-S107

17. Karaskov E, Scott C, Zhang L, Teodoro T, Ravazzola M, Volchuk A (2006) Chronic palmitate but not oleate exposure induces endoplasmic reticulum stress, which may contribute to INS-1 pancreatic $\beta$-cell apoptosis. Endocrinology 147:3398-3407

18. Pirot P, Eizirik DL, Cardozo AK (2006) Interferon-gamma potentiates endoplasmic reticulum stress-induced death by reducing pancreatic beta cell defence mechanisms. Diabetologia 49:1229-1236 
19. Zhou YP, Teng D, Dralyuk F et al (1998) Apoptosis in insulinsecreting cells. Evidence for the role of intracellular $\mathrm{Ca}^{2+}$ stores and arachidonic acid metabolism. J Clin Invest 101:1623-1632

20. Magnusson NE, Cardozo AK, Kruhoffer M, Eizirik DL, Orntoft TF, Jensen JL (2005) Construction and validation of the APOCHIP, a spotted oligo-microarray for the study of beta-cell apoptosis. BMC Bioinformatics 6:311

21. Rasschaert J, Ladriere L, Urbain M et al (2005) Toll-like receptor 3 and STAT-1 contribute to double-stranded RNA+ interferongamma-induced apoptosis in primary pancreatic beta-cells. J Biol Chem 280:33984-33991

22. Kutlu B, Cardozo AK, Darville MI et al (2003) Discovery of gene networks regulating cytokine-induced dysfunction and apoptosis in insulin-producing INS-1 cells. Diabetes 52:2701-2719

23. Wilson DL, Buckley MJ, Helliwell CA, Wilson IW (2003) New normalization methods for cDNA microarray data. Bioinformatics 19:1325-1332

24. Storey JD, Tibshirani R (2003) Statistical significance for genome-wide studies. Proc Natl Acad Sci USA 100:9440-9445

25. Kutlu B, Naamane N, Berthou L, Eizirik DL (2004) New approaches for in silico identification of cytokine-modified beta cell gene networks. Ann NY Acad Sci 1037:41-58

26. Cardozo AK, Kruhoffer M, Leeman R, Orntoft T, Eizirik DL (2001) Identification of novel cytokine-induced genes in pancreatic beta-cells by high-density oligonucleotide arrays. Diabetes 50:909-920

27. Green LC, Wagner DA, Glogowski J, Skipper PL, Wishnok JS, Tannenbaum SR (1982) Analysis of nitrate, nitrite, and [15N] nitrate in biological fluids. Anal Biochem 126:131-138

28. Chepurny OG, Hussain MA, Holz GG (2002) Exendin-4 as a stimulator of rat insulin I gene promoter activity via bZIP/CRE interactions sensitive to serine/threonine protein kinase inhibitor Ro 31-8220. Endocrinology 143:2303-2313

29. Dooley TP, Curto EV, Davis RL, Grammatico P, Robinson ES, Wilborn TW (2003) DNA microarrays and likelihood ratio bioinformatic methods: discovery of human melanocyte biomarkers. Pigment Cell Res 16:245-253

30. Brewer JW, Hendershot LM, Sherr CJ, Diehl JA (1999) Mammalian unfolded protein response inhibits cyclin D1 translation and cell-cycle progression. Proc Natl Acad Sci USA 96:8505-8510

31. Hendershot LM (2004) The ER function BiP is a master regulator of ER function. Mt Sinai J Med 71:289-297

32. Gelebart P, Opas M, Michalak M (2005) Calreticulin, a $\mathrm{Ca}^{2+}$ binding chaperone of the endoplasmic reticulum. Int $\mathrm{J}$ Biochem Cell Biol 37:260-266

33. Argon Y, Simen BB (1999) GRP94, an ER chaperone with protein and peptide binding properties. Semin Cell Dev Biol 10:495-505

34. Romisch K (1999) Surfing the Sec61 channel: bidirectional protein translocation across the ER membrane. J Cell Sci 112:4185-4191

35. Harding HP, Zhang Y, Zeng $\mathrm{H}$ et al (2003) An integrated stress response regulates amino acid metabolism and resistance to oxidative stress. Mol Cell 11:619-633
36. Ma Y, Brewer JW, Diehl JA, Hendershot LM (2002) Two distinct stress signaling pathways converge upon the CHOP promoter during the mammalian unfolded protein response. J Mol Biol 318:1351-1365

37. Pirot P, Ortis F, Cnop M et al (2007) Transcriptional regulation of the endoplasmic reticulum (ER) stress gene Chop in pancreatic insulin producing cells. Diabetes DOI: $10.2337 / \mathrm{db} 06-1253$

38. McCullough KD, Martindale JL, Klotz LO, Aw TY, Holbrook NJ (2001) Gadd153 sensitizes cells to endoplasmic reticulum stress by down- regulating $\mathrm{Bcl} 2$ and perturbing the cellular redox state. Mol Cell Biol 21:1249-1259

39. Nakagawa T, Zhu H, Morishima N et al (2000) Caspase-12 mediates endoplasmic-reticulum-specific apoptosis and cytotoxicity by amyloid-beta. Nature 403:98-103

40. Steiner DF, Rouille Y, Gong Q, Martin S, Carroll R, Chan SJ (1996) The role of prohormone convertases in insulin biosynthesis: evidence for inherited defects in their action in man and experimental animals. Diabetes Metab 22:94-104

41. Lang J (1999) Molecular mechanisms and regulation of insulin exocytosis as a paradigm of endocrine secretion. Eur J Biochem 259:3-17

42. Chakrabarti SK, Mirmira RG (2003) Transcription factors direct the development and function of pancreatic beta cells. Trends Endocrinol Metab 14:78-84

43. Hansen BS, Nielsen JH, Linde S (1988) Effect of interleukin-1 on the biosynthesis of proinsulin and insulin in isolated rat pancreatic islets. Biomed Biochim Acta 47:305-309

44. Hostens K, Pavlovic D, Zambre Y et al (1999) Exposure of human islets to cytokines can result in disproportionately elevated proinsulin release. J Clin Invest 104:67-72

45. Ohara-Imaizumi M, Cardozo AK, Kikuta T, Eizirik DL, Nagamatsu S (2004) The cytokine interleukin-1beta reduces the docking and fusion of insulin granules in pancreatic beta-cells, preferentially decreasing the first phase of exocytosis. J Biol Chem 279:41271-41274

46. Spinas GA, Hansen BS, Linde S et al (1987) Interleukin 1 dosedependently affects the biosynthesis of (pro)insulin in isolated rat islets of Langerhans. Diabetologia 30:474-480

47. Eizirik DL, Welsh M, Strandell E, Welsh N, Sandler S (1990) Interleukin-1 beta depletes insulin messenger ribonucleic acid and increases the heat shock protein hsp70 in mouse pancreatic islets without impairing the glucose metabolism. Endocrinology 127:2290-2297

48. Eizirik DL (1991) Interleukin-1 beta induces an early decrease in insulin release, (pro)insulin biosynthesis and insulin mRNA in mouse pancreatic islets by a mechanism dependent on gene transcription and protein synthesis. Autoimmunity 10:107-113

49. Lipson KL, Fonseca SG, Ishigaki S et al (2006) Regulation of insulin biosynthesis in pancreatic beta cells by an endoplasmic reticulum-resident protein kinase IRE1. Cell Metab 4:245-254

50. Laybutt DR, Preston AM, Akerfeldt MC et al (2007) Endoplasmic reticulum stress contributes to beta cell apoptosis in type 2 diabetes. Diabetologia. DOI 10.1007/s00125-006-0590-z 